\title{
Inhibition of Paracoccidioides brasiliensis by ajoene is associated with blockade of phosphatidylcholine biosynthesis
}

\author{
Gioconda San-Blas, ${ }^{1}$ Julio A. Urbina, ${ }^{2}$ Edgar Marchán, ${ }^{2}$ Lellys M. \\ Contreras, ${ }^{2}$ Françoise Sorais ${ }^{1}$ and Felipe San-Blas ${ }^{1}$
}

\author{
Author for correspondence: Gioconda San-Blas. Tel: +58 2504 1040. Fax: +58 25041382. \\ e-mail: gsanblas@pasteur.ivic.ve
}

Instituto Venezolano de Investigaciones Científicas (IVIC), Centres of Microbiology and Cell Biology ${ }^{1}$ and Biophysics and Biochemistry, ${ }^{2}$ Apartado 21827, Caracas 1020A, Venezuela

\begin{abstract}
In Paracoccidioides brasiliensis, a dimorphic fungus pathogenic for humans, no significant differences were observed in the phospholipid species of both morphological phases. The species observed were phosphatidylcholine (PC, 30-40\%), phosphatidylethanolamine (PE, 27-28\%), phosphatidylserine (16-19\%), phosphatidylinositol (13-17\%) and sphingomyelin (3-5\%). The main fatty acids found in the yeast $(Y)$ phase were palmitate $(56 \%)$, linoleate $(18 \%)$ and oleate $(15 \%)$, while linoleate predominated $(61 \%)$ in the mycelial (M) phase, followed by palmitate $(27 \%)$ and oleate $(7 \%)$. In the $Y$ phase the main free sterol was ergosta-5,22-dien-3 $\beta$-ol $(82 \%)$ plus some lanosterol $(12 \%)$ and ergosterol $(6 \%)$, while in the $M$ phase, the latter predominated $(88 \%)$, followed by low levels of ergosta-5,22-dien-3 $\beta$-ol $(12 \%)$. Ajoene $[(E, Z)-4,5,9$ trithiadodeca-1,6,11-triene 9-oxide], a platelet aggregation inhibitor derived from garlic, induced alterations in phospholipid and fatty acid proportions such that PC was reduced to about $18 \%$ in both phases and PE increased to $38 \%$ ( $Y$ phase) or $\mathbf{4 4 \%}$ ( $M$ phase), suggesting inhibition of PC synthesis. Ajoene also reduced saturated fatty acids (16:0 and 18:0) from 67 to $35 \%$ in the $Y$ phase, with a corresponding increase in the unsaturated components. This effect was not seen in the $M$ phase.
\end{abstract}

Keywords: fungal dimorphism, Paracoccidioides brasiliensis, ajoene, antifungal drugs, fungal lipids

\section{INTRODUCTION}

Paracoccidioides brasiliensis is a thermally dimorphic fungus and the causative agent of a prevalent human systemic mycosis in Latin America where it is geographically constrained (Wanke \& Londero, 1994). The pathogenic yeast-like $(\mathrm{Y})$ phase grows at $37^{\circ} \mathrm{C}$, while a mycelial (M) phase develops at $23^{\circ} \mathrm{C}$ (Lacaz, 1994). Ajoene $[(E, Z)-4,5,9$-trithiadodeca-1,6,11-triene 9-oxide], a platelet aggregation inhibitor derived from garlic (Apitz-Castro et al., 1983), behaves as an antifungal agent against $P$. brasiliensis (San-Blas et al., 1989), Aspergillus niger and Candida albicans (Yoshida et al., 1987), Cladosporium carrionii and Fonsecaea pedrosoi (Sánchez-Mirt et al., 1993). Ajoene disturbs the fungal

Abbreviations: $\mathrm{PC}$, phosphatidylcholine; $\mathrm{PE}$, phosphatidylethanolamine; PI, phosphatidylinositol; PS, phosphatidylserine; SFA, saturated fatty acids; UFA, unsaturated fatty acids. plasma membrane (San-Blas et al., 1989; Sánchez-Mirt et al., 1993), an effect that is more prevalent in the $\mathrm{Y}$ phase in $P$. brasiliensis. Membrane disturbance leads to the deterioration of fungal structures, among them the cell wall, whose synthesis depends on the correct performance of the enzymic machinery located in the plasma membrane (San-Blas \& San-Blas, 1994). Ajoene is also capable of blocking the thermally induced transition from the $M$ to the $Y$ phase (San-Blas et al., 1993b), an effect that together with the already mentioned effect on growth, may be of interest in therapy, since the transition process is the first requirement for the establishment of paracoccidioidomycosis in the host (Lacaz, 1994).

Recently, it was shown that ajoene also acts as an antiproliferative drug against the epimastigote and amastigote forms of Trypanosoma cruzi, the causative agent of Chagas disease (Urbina et al., 1993), an effect associated with a specific blockade of the de novo 
synthesis of phosphatidylcholine, the main phospholipid species of these cells. Here we report the effects of ajoene on the lipid composition of $Y$ and $M$ phase cells of $P$. brasiliensis. Our results suggest a biochemical mechanism of action similar to that proposed for T. cruzi.

\section{METHODS}

Fungus and growth conditions. $P$. brasiliensis strain IVIC Pb73 (ATCC 32071) has been maintained in our laboratory on PYG medium (per litre distilled water: peptone, $5 \mathrm{~g}$; yeast extract, $5 \mathrm{~g}$; glucose, $15 \mathrm{~g}$; final $\mathrm{pH} 7 \cdot 0$ ) agar slants for several years. It was grown in PYG liquid medium $(200 \mathrm{ml}$ medium in $500 \mathrm{ml}$ Erlenmeyer flasks) after inoculation with $10 \mathrm{ml}$ of a seed culture. The cultures were incubated for $3 \mathrm{~d}$ at $37^{\circ} \mathrm{C}(\mathrm{Y}$ phase) or $23^{\circ} \mathrm{C}$ ( $\mathrm{M}$ phase) with continuous shaking on a gyratory shaker operated at 120 r.p.m. (Sorais-Landáez \& San-Blas, 1993). Ajoene $(25 \mathrm{mM}$ for the $Y$ phase, $50 \mathrm{mM}$ for the $M$ phase) was added to the culture medium at time zero to inhibit growth by $50 \%$ (San-Blas et al., 1989). It was prepared for use as a $100 \mathrm{mM}$ solution in ethanol. Cultures with the addition of equivalent volumes of ethanol in the absence of ajoene were used as controls. Ajoene was the kind gift of Dr R. Apitz-Castro (R. Apitz-Castro \& M.K. Jain, US patent 4665088, May 1987).

Lipid analysis. $Y$ and $M$ cultures of $P$. brasiliensis were washed three times by centrifugation ( $Y$ phase) or filtration ( $M$ phase) and total lipids extracted with chloroform/methanol $(2: 1$; $\mathrm{v} / \mathrm{v}$ ). Polar and neutral lipids were separated by silicic acid column chromatography (Larralde et al., 1988). Polar lipids were fractionated by TLC using high performance plates (Merck 5715) with chloroform/methanol/30\% aqueous ammonia (17:7:1, by vol.) as eluent (Cuzner \& Davison, 1967); the different species were quantified by measuring organic phosphate content (Ames \& Dubin, 1960). Fatty acids esterified to the lipid fraction were converted to their methyl esters by incubation in the presence of $2 \% \mathrm{H}_{2} \mathrm{SO}_{4}$ in methanol at $60^{\circ} \mathrm{C}$ for $1 \mathrm{~h}$ (Urbina et al., 1993). The neutral lipid fraction was analysed by GLC in a Varian 3700 Gas Chromatograph equipped with a flame ionization detector as described previously (Urbina et al., 1993). For structural assignments, this fraction was also analysed in a capillary high resolution column $(25 \mathrm{~m} \times 0.20 \mathrm{~mm}$ i.d. Hewlett-Packard HP-5 MS column with $5 \%$ phenylmethylsiloxane, $0.33 \mathrm{~mm}$ film thickness) using a Hewlett-Packard 5890 Series II Gas Chromatograph equipped with a 5971A Mass Sensitive Detector. The lipids were injected in ethyl acetate and the column kept at $50^{\circ} \mathrm{C}$ for $1 \mathrm{~min}$, followed by a temperature increase to $270^{\circ} \mathrm{C}$

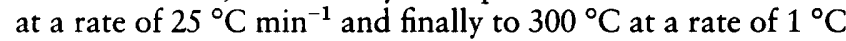
$\min ^{-1}$. The carrier gas (He) flow was kept constant at $1 \mathrm{ml}$ $\min ^{-1}$. The injector temperature was fixed at $250^{\circ} \mathrm{C}$ and that of the detector at $280^{\circ} \mathrm{C}$.

\section{RESULTS AND DISCUSSION}

No significant differences were observed in the phospholipid species of either morphological phase of $P$. brasiliensis (Table 1). Phosphatidylcholine (PC) was the main species in both $\mathrm{Y}$ and $\mathrm{M}$ cells (30.5 and $39.7 \%$, respectively), followed by phosphatidylethanolamine (PE, 27.7 and $28.7 \%$ ), phosphatidylserine (PS, 15.8 and $19 \cdot 0 \%$ ), and phosphatidylinositol (PI, $13 \cdot 1$ and $17 \cdot 8 \%$ ). Therefore, their proposed role in $P$. brasiliensis dimorphism (Manocha, 1980) is questioned. These results contrast with those found in C. albicans whose $M$ form contains significantly higher levels of PC, PS and PI, and lower levels of PE, compared to the Y form (Goyal \& Khuller, 1994).

The predominant fatty acid in control $\mathrm{Y}$ cells was palmitate $(16: 0 ; 56.2 \%)$, followed by linoleate $(18: 2$; $18.2 \%$ ) and oleate $(18: 1 ; 14.9 \%)$ (Table 2$)$. In the $M$ phase, linoleate was by far the most abundant component $(61 \cdot 1 \%)$, followed by palmitate $(26.8 \%)$ and much lower levels of oleate $(5 \%)$. Stearate $(18: 0)$ was a minor component in both phases $(5 \cdot 5-10 \cdot 7 \%)$. These results agree with those of Manocha (1980) on the predominance of palmitate $(16: 0)$ in the $Y$ phase and linoleate $(18: 2)$ in the $M$ phase. As reported in $C$. albicans (Ghannoum et al., 1986; Mishra et al., 1992; Goyal \& Khuller, 1994), the ratio of unsaturated to saturated fatty acids (UFA/SFA) was higher in the $M$ form of $P$. brasiliensis (Table 2). The higher levels of SFA in the $Y$ form are probably required to maintain normal basic permeability properties of the plasma membranes at its relatively high growth temperature (Goyal \& Khuller, 1994). As in P. brasiliensis, the lowering of growth temperature increases fatty acid unsaturation in Aspergillus niger, Penicillium chrysogenum and Trichoderma reesei, but not in Neurospora crassa where unsaturation remains unchanged (Suutari, 1995).

Ajoene is an inhibitor of in vitro growth of $P$. brasiliensis (San-Blas et al., 1989), although not as potent as sulfonamides (Restrepo \& Arango, 1980), azoles and amphotericin B (Restrepo et al., 1984; San-Blas et al., 1993a). It provokes important changes in the plasma membrane, without any noticeable direct effect on the cell wall (San-Blas et al., 1989). Analysis of the cellular phospholipid content showed that ajoene induced a reversal of the relative proportion of the main phospholipid species in both $Y$ and $M$ phases (Table 1), leading to a predominance of PE $(38.2$ and $43.6 \%$ in the $Y$ and $M$ phases, respectively), in contrast with data from untreated cells. The proportions of PS $(14.6$ and $20.9 \%$, respectively), PI (13.1 and $18.1 \%)$ and sphingomyelin $(2.7$ and $5.0 \%)$ were not significantly affected. Therefore, while ajoene $(200 \mu \mathrm{M})$ does not induce any marked changes in the ultrastructure of blood platelets from human or other mammalian species (Apitz-Castro et al., 1988), it seems highly selective for the fungal membrane where it modifies the headgroup composition of $P$. brasiliensis phospholipids, similar to the effect of aqueous garlic extracts (AGE) on C. albicans (Adetumbi et al., 1986; Ghannoum, 1988). Compositional changes of this type should lead to a very unstable lipid bilayer, consistent with the ultrastructural results obtained previously (San-Blas et al., 1989). Treatment of Y cells with ajoene (Table 2 ) also produced a drastic reduction in SFA (16:0 and 18:0) $(67 \%-35 \%)$ with a concomitant increase $(33 \%-65 \%)$ of the UFA $(18: 1$ and $18: 2)$, leading to a UFA/SFA ratio similar to that of the $M$ phase. The large increase in UFA in the $Y$ phase could lead to loss of vital cytoplasmic components in the treated cells. On the other hand, no significant modifica- 
Table 1. Effect of ajoene on phospholipid composition of $P$. brasiliensis

The results, expressed as mol\%, are means \pm SEM of three independent experiments.

\begin{tabular}{|c|c|c|c|c|}
\hline \multirow[t]{2}{*}{ Phospholipid species } & \multicolumn{2}{|c|}{ Y phase } & \multicolumn{2}{|c|}{$M$ phase } \\
\hline & Control & $\begin{array}{c}+25 \mathrm{mM} \\
\text { ajoene }\end{array}$ & Control & $\begin{array}{c}+50 \mathrm{mM} \\
\text { ajoene }\end{array}$ \\
\hline PC & $30 \cdot 5 \pm 4 \cdot 1$ & $17 \cdot 2 \pm 2 \cdot 5$ & $39 \cdot 7 \pm 3 \cdot 8$ & $19.4 \pm 3.6$ \\
\hline $\mathrm{PE}$ & $27 \cdot 7 \pm 3 \cdot 4$ & $38 \cdot 2 \pm 4 \cdot 0$ & $28 \cdot 7 \pm 3 \cdot 5$ & $43 \cdot 6 \pm 5 \cdot 0$ \\
\hline PS & $19 \cdot 0 \pm 2 \cdot 4$ & $20 \cdot 9 \pm 2 \cdot 5$ & $15 \cdot 8 \pm 2 \cdot 8$ & $14 \cdot 6 \pm 3 \cdot 0$ \\
\hline PI & $17 \cdot 8 \pm 2 \cdot 3$ & $19 \cdot 8 \pm 2 \cdot 6$ & $13 \cdot 1 \pm 2 \cdot 6$ & $18 \cdot 5 \pm 3 \cdot 0$ \\
\hline Sphingomyelin & $5 \cdot 0 \pm 1 \cdot 2$ & $3 \cdot 9 \pm 1 \cdot 1$ & $2 \cdot 7 \pm 0.9$ & $3 \cdot 9 \pm 1 \cdot 0$ \\
\hline
\end{tabular}

Table 2. Effect of ajoene on fatty acid composition of $P$. brasiliensis

The results, expressed as mol $\%$, are means \pm SEM of three independent experiments.

\begin{tabular}{|c|c|c|c|c|}
\hline \multirow[t]{2}{*}{ Fatty acid species } & \multicolumn{2}{|c|}{ Y phase } & \multicolumn{2}{|c|}{ M phase } \\
\hline & Control & $\begin{array}{c}+25 \mathrm{mM} \\
\text { ajoene }\end{array}$ & Control & $\begin{array}{c}+50 \mathrm{mM} \\
\text { ajoene }\end{array}$ \\
\hline $16: 0$ & $56 \cdot 2 \pm 5 \cdot 3$ & $32 \cdot 3 \pm 3 \cdot 6$ & $26 \cdot 8 \pm 1 \cdot 1$ & $28 \cdot 7 \pm 1 \cdot 5$ \\
\hline $18: 0$ & $10 \cdot 7 \pm 3 \cdot 2$ & $2.6 \pm 0.5$ & $5 \cdot 5 \pm 0.3$ & $6 \cdot 3 \pm 1 \cdot 0$ \\
\hline $18: 1$ & $14.9 \pm 0.7$ & $23 \cdot 9 \pm 3 \cdot 8$ & $6 \cdot 6 \pm 0 \cdot 1$ & $5 \cdot 0 \pm 1 \cdot 7$ \\
\hline $18: 2$ & $18 \cdot 2 \pm 4 \cdot 0$ & $41 \cdot 2 \pm 1 \cdot 9$ & $61 \cdot 1 \pm 1 \cdot 3$ & $60 \cdot 0 \pm 4 \cdot 2$ \\
\hline SFA & $66.9 \pm 6.9$ & $34 \cdot 9 \pm 4 \cdot 2$ & $32 \cdot 3 \pm 1 \cdot 5$ & $35 \cdot 0 \pm 2 \cdot 3$ \\
\hline UFA & $33 \cdot 1 \pm 4 \cdot 5$ & $65 \cdot 1 \pm 5 \cdot 5$ & $67 \cdot 7 \pm 1 \cdot 4$ & $65 \cdot 0 \pm 5 \cdot 2$ \\
\hline UFA/SFA & $0 . \overline{49}$ & $1 \cdot \overline{87}$ & $2 \cdot \overline{10}$ & $1 \cdot \overline{86}$ \\
\hline
\end{tabular}

tion of the SFA/UFA ratio was observed in M cultures when ajoene was added to them.

Azoles (ketoconazole, itraconazole and saperconazole) (San-Blas et al., 1993a) are very effective growth inhibitors against $P$. brasiliensis, indicating that the fungus requires specific 4,14-desmethyl sterols of the ergosta type for growth. The neutral lipid fraction of $P$. brasiliensis, $\mathrm{Y}$ phase, contained ergosta-5,22-dien- $3 \beta$-ol $(82 \%)$ as the main free sterol, plus much lower amounts of lanosterol $(12 \%)$ and ergosterol $(6 \%)$. In the $M$ phase, the predominant sterol was ergosterol $(88 \%)$, accompanied by lower levels of ergosta-5,22-dien-3 $\beta$-ol $(12 \%)$. These results contrast with previous ones in five strains of $P$. brasiliensis (Hamdam et al., 1993) in which ergosterol and squalene comprised the bulk of sterol fraction. The presence of ergosta-5,22-dien-3 $\beta$-ol instead of ergosterol in P. brasiliensis ( $\mathrm{Y}$ phase $>\mathrm{M}$ phase), though unusual, should only lead to minor differences in the properties of the plasma membrane, in contrast with the abrupt changes provoked when cholesterol, rather than ergosterol, is incorporated. T. cruzi, another polymorphic micro-organism, had ergosterol and its 24ethyl analogue in the membranes of the epimastigote phase, while amastigotes modified these sterols with the exclusion of the 5,22 double bonds (J. A. Urbina and others, unpublished results). In C. albicans, enzymic defects in ergosterol-deficient (erg) mutants lead to the accumulation of intermediates such as ergosta-7-en-3 $\beta$ ol or ergosta-7,22-dien-3 $\beta$-ol which were able to sustain the growth of erg mutants without any auxotrophic requirement for sterols. However, the depletion of ergosterol resulted in reduced assimilation of glycerol, DL-lactic acid, L-sorbose and other compounds, and to decreased amino acid transport activity (Mishra et al., 1992). Whether this is the case with both phases of $P$. brasiliensis remains to be studied. In contrast with the marked effects of ajoene on the phospholipid headgroup and fatty acid composition, no significant effects were observed in the sterol composition of either phase in the presence of ajoene.

In conclusion, the antiproliferative effects of ajoene in $P$. brasiliensis were associated with a marked reduction in the content of PC, with a concomitant increase in the levels of its precursor PE and a large increase in the amounts of unsaturated fatty acids in the $\mathrm{Y}$ phase. This may provide an explanation for the observed alteration of the physical properties of the plasma membrane (SanBlas et al., 1989) and could also lead to modifications in the activities of key membrane enzymes. These biochemical effects are remarkably similar to those reported 
previously for the protozoon T. cruzi (Urbina et al., 1993), suggesting a common antiproliferative mechanism of ajoene against lower eukaryotes and resulting in a novel mechanism of antifungal action.

\section{ACKNOWLEDGEMENTS}

To Dr Rafael Apitz-Castro for kindly providing samples of ajoene. This project was partially financed by the World Bank/World Health Organization/PNUD Special Programme of Research and Training on Tropical Diseases grant OMS/ TDR 930161 (J.A.U.).

\section{REFERENCES}

Adetumbi, M., Javor, G. T. \& Lau, B. H. S. (1986). Allium sativum (garlic) inhibits lipid synthesis by Candida albicans. Antimicrob Agents Chemother 30, 499-501.

Ames, B. N. \& Dubin, D. T. (1960). The role of polyamines in the neutralization of deoxyribonucleic acid. $J$ Biol Chem 235, 769-775.

Apitz-Castro, R., Cabrera, S., Cruz, M. R., Ledezma, E. \& Jain, M. K. (1983). Effect of garlic extracts and of three pure components isolated from it on human platelet aggregation, arachidonate metabolism, release reaction and platelet ultrastructure. Thromb Res 42, 155-169.

Apitz-Castro, R., Ledezma, E., Escalante, J., Jorquera, A., Piñate, F., Moreno-Rea, J., Carrillo, G., Leal, O. \& Jain, M. K. (1988). Ajoene [(E,Z)-4,5,9-trithiadodeca-1,6,11-triene 9-oxide] reversibly prevents platelet activation in dogs under extracorporeal circulation. Arzneim-Forsch 38, 901-904.

Cuzner, M. L. \& Davison, A. N. (1967). Quantitative thin layer chromatography of lipids. J Chromatogr 27, 388-397.

Ghannoum, M. A. (1988). Studies on the anticandidal mode of action of Allium sativum (garlic). J Gen Microbiol 134, 29172924.

Ghannoum, M. A., Janini, G., Khamis, L. \& Radwan, S. S. (1986). Dimorphism-associated variations in the lipid composition of Candida albicans. J Gen Microbiol 132, 2367-2375.

Goyal, S. \& Khuller, G. K. (1994). Structural and functional role of lipids in yeast and mycelial forms of Candida albicans. Lipids 29, 793-797.

Hamdan, J. S., Resende, M. A., Cunha, A. L., Alves, C. H. \& Cisalpino, E. O. (1993). Partial biochemical characterization of five Paracoccidioides brasiliensis strains. Curr Microbiol 27, 91-95.

Lacaz, C. S. (1994). Paracoccidioides brasiliensis: morphology, evolutionary cycle; maintenance during saprophytic life; biology, virulence, taxonomy. In Paracoccidioidomycosis, pp. 13-25. Edited by M. Franco, C. S. Lacaz, A. Restrepo-Moreno \& G. Del Negro. Boca Raton: CRC Press.

Larralde, G., Vivas, J. \& Urbina, J. A. (1988). Concentration and time-dependence of the effects of ketoconazole on growth and sterol synthesis by Trypanosoma (Schizotrypanum) cruzi epimastigotes. Acta Cient Venez 39, 140-146.
Manocha, M. S. (1980). Lipid composition of Paracoccidioides brasiliensis: comparison between the yeast and mycelial forms. Sabouraudia 18, 281-286.

Mishra, P., Bolard, J. \& Prasad, R. (1992). Emerging role of lipids in Candida albicans, a pathogenic dimorphic yeast. Biochim Biophys Acta 1127, 1-14.

Restrepo, A. \& Arango, M. D. (1980). In vitro susceptibility testing of Paracoccidioides brasiliensis to sulfonamides. Antimicrob Agents Chemother 18, 190-194.

Restrepo, A., De Bedoutand, C. \& Tabares, A. M. (1984). In vitro susceptibility of Paracoccidioides brasiliensis yeast form to antifungal agents. Rev Inst Med Trop Sao Paulo 26, 322-328.

San-Blas, G. \& San-Blas, F. (1994). Biochemistry of Paracoccidioides brasiliensis dimorphism. In Paracoccidioidomycosis, pp. 49-66. Edited by M. Franco, C. S. Lacaz, A. Restrepo-Moreno \& G. Del Negro. Boca Raton: CRC Press.

San-Blas, G., San-Blas, F., Gil, F., Mariño, L. \& Apitz-Castro, R. (1989). Inhibition of growth of the dimorphic fungus Paracoccidioides brasiliensis by ajoene. Antimicrob Agents Chemother 33, 1641-1644.

San-Blas, G., Calcagno, A. M. \& San-Blas, F. (1993a). A preliminary study of in vitro antibiotic activity of saperconazole and other azoles on Paracoccidioides brasiliensis. J Med Vet Mycol 31, 169-174.

San-Blas, G., Mariño, L., San-Blas, F. \& Apitz-Castro, R. (1993b). Effect of ajoene on dimorphism of Paracoccidioides brasiliensis. $J$ Med Vet Mycol 31, 133-141.

Sánchez-Mirt, A., Gil, F. \& Apitz-Castro, R. (1993). In vitro inhibitory effect and ultrastructural alterations caused by ajoene on the growth of dematiaceous fungi: Cladosporium carrionii and Fonsecaea pedrosoi. Rev Iberoam Micol 10, 74-78.

Sorais-Landáez, F. \& San-Blas, G. (1993). Localization of $\beta-1,3-$ glucan synthetase in membranes of Paracoccidioides brasiliensis. J Med Vet Mycol 31, 421-426.

Suutari, M. (1995). Effect of growth temperature on lipid fatty acids of four fungi (Aspergillus niger, Neurospora crassa, Penicillium chrysogenum and Trichoderma reesei). Arch Microbiol 164, 212-216.

Urbina, J. A., Marchán, E., Lazardi, K., Visbal, G., Apitz-Castro, R., Gil, F., Aguirre, T., Piras, M. M. \& Piras, R. (1993). Inhibition of phosphatidylcholine biosynthesis and cell proliferation in Trypanosoma cruzi by ajoene, an antiplatelet compound isolated from garlic. Biochem Pharmacol 45, 2381-2387.

Wanke, B. \& Londero, A. T. (1994). Epidemiology and paracoccidioidomycosis infection. In Paracoccidioidomycosis, pp. 109-120. Edited by M. Franco, C. S. Lacaz, A. Restrepo-Moreno \& G. Del Negro. Boca Raton: CRC Press.

Yoshida, S., Kasuga, S., Hayashi, N., Ushiroguchi, T., Matsuura, H. \& Nakagawa, S. (1987). Antifungal activity of ajoene derived from garlic. Appl Environ Microbiol 53, 615-617.

Received 22 October 1996; revised 26 November 1996; accepted 19 December 1996. 